\title{
Unconventional Adulterants in Seized Heroin Samples: Forensic Insight
}

\author{
Kavita Goyal ${ }^{1}$, Neha Tomar ${ }^{2}$, Sweta Sinha ${ }^{3 *}$, Rakesh Kumar ${ }^{4}$ \& Sunil Kumar Mahato ${ }^{5}$ \\ ${ }^{I}$ Assistant Director, Chemistry, Forensic Science Laboratory, Rohini, Delhi, India. ${ }^{2}$ Assistant Professor, Amity Institute of Forensic \\ Science, Amity University, UP, Noida, India. ${ }^{3,4}$ Chemical Examiner, Chemistry, Forensic Science Laboratory, Rohini, Delhi, India. \\ ${ }^{5}$ Scientific Assistant, Forensic Science Laboratory, Rohini, Delhi, India. *Corresponding Author Email: sweta.fsl@gmail.com
}

Copyright: @2020 Kavita Goyal et al. This is an open access article distributed under the terms of the Creative Commons Attribution License, which permits unrestricted use, distribution, and reproduction in any medium, provided the original author and source are credited.

\section{ABSTRACT}

Drug abuse is a global predicament. The illicit market of drugs consistently witnesses experiments to deceive law regulatory agencies during manufacturing and trading of these regulated drugs. Drug traders amalgamate core drug compound with other chemical moieties to deceive regulatory agencies, to enhance potency and to escalate the tempt for consumption. Diacetylmorphine, commonly called smack/heroin is substantially seized round the globe, which clearly indicates its large scale abuse. This study presents some unusual additives in 252 seized samples for suspected heroin, referred to Forensic Science Laboratory (FSL), Delhi in the year 2019. The samples were isolated, screened and identified using GC-MS technique. Besides other consistent additives, four unusual novel adulterants were detected in confiscated heroin samples in Delhi, India. The study will update forensic chemical experts in detection of new adulterants in seized drugs, besides disseminating awareness and knowledge among those concerned with drug regulation, monitoring and policy making.

Keywords: Adulterants: Diacetylmorphine, Drug abuse: Gas chromatography-mass spectroscopy (GC-MS), Forensic.

\section{Introduction}

Drug abuse is increasing at an alarming rate and has turned out to be major global concern. National and International regulatory authorities are working strenuously to combat and check this crime. Despite stringent measures, manufacture and trade of illicit drugs for abuse has increased manifolds ${ }^{(1)}$. National Survey on substance abuse conducted in India in 2017-18 reports heroin to be the most commonly abused opioid and this is even evident from its steadily escalating seizures ${ }^{(2)}$.

Opium and its derivatives have always outshined the list of drug abuse, illegal production and trade. Heroin, which despite strict check, has maintained a consistent trade in India and throughout the globe ${ }^{(3)}$. Pure heroin, chemically known as Diacetylmorphine (DAM), is fine white crystalline powder, but due to inappropriate manufacturing, adulterants and effects of environment, a change in its appearance is often noticed.

Opium (derived from plant Papaver sonmiferum) contains a latex with two major group of alkaloids: the psychoactive constituents affecting the central nervous system (CNS) called phenanthrenes (comprising morphine, codeine and thebaine) and the other group, isoquinolines (comprising Papaverine and narcotine) having no effect on central nervous system ${ }^{(4)}$. All alkaloids of opium possess significant potential to cause addiction ${ }^{(5)}$.

Heroin falls in the category of controlled drug because of its extensive abuse. Drug abuse results in proportional increase in crime rate including illegal trafficking of drugs. The illegal trafficking of drug encourages illicit manufacturers to resort to adulteration to make profit, affecting the society economically as well as posing serious health threat to the abuser. Although, diacetylmorphine has been used as analgesic in chronic pain since decades. In human body, diacetylmorphine metabolizes to morphine before crossing Blood Brain Barrier (BBB) and 
produces effect on central nervous system (CNS) opioid receptors, therefore, it has high potential to cause addiction (Huecker, Koutsothanasis, Abbasy, Marraffa, 2020).

The abused drugs are often manufactured in clandestine laboratories to deceive law enforcement agencies and in the process, are also adulterated to maximise the profit. Adulterants, are usually those compounds which are easily available at low cost - adding to the volume of final products, also, they sometimes include chemical compounds that help to enhance the potency of the drug. Nontoxic adulterants e.g., milk powder, talc, sugar etc., better known as diluents, increase the quantity without disturbing the potency of drug, whereas other additives may have toxic effect on chronic exposure ${ }^{(7-8)}$. Another, major aggravated problem associated with these adulterants is the fact that, before distributing such drugs in market for sale, no toxicological analysis is performed to understand their ill effects on abusers, and consequent risk to life ${ }^{(9)}$. Undetermined toxic analysis and the potential for unanticipated synergistic responses of adulterated drugs when consumed with other intoxicants enhance the risk for adverse health consequences ${ }^{(10)}$. As there exists, a very thin line between recreational and fatal dose, there is always an added risk ${ }^{(11-12)}$. Therefore, the presence of adulterants with potential to boost toxic effect, needs serious consideration and its identification an important task.

India being a signatory to Single Convention on N arcotic Drugs (1961) and the Convention on Psychotropic Substances (1971) thereby, adhere control through the Narcotic Drugs and Psychotropic Substances Act, 1985 and its subsequent amendments, to monitor the use and abuse of illicit drugs. In spite of stringent laws and punishments, illicit drugs remain accessible to the user, no matter how draconian the penalties imposed. It further becomes an organised network with vested interest resulting in spiralling petty crimes in society usually driven by the need to obtain more money for drugs. Scientists have witnessed novel trends in addition of impurities, adulterants and diluents over the years ${ }^{(13-14)}$. Introduction of new, hitherto unknown adulterants add layer of complexity during chemical analysis and subsequent interpretation. Therefore, the onus lies on the Forensic chemical examiner to update the global community regarding constituents of adulterants in confiscated samples and contribute towards data for current trends in drug abuse. This study at Forensic Science Laboratory, Delhi (FSL) aims to uncover the newly detected adulterants in reported cases from national capital territory of Delhi, India, in the year 2019.

\section{Experimental Analysis ${ }^{(15-17)}$}

\section{Material \& Methods}

\subsection{Chemicals, Reagents and Reference Material}

Chemicals- Methanol, chloroform, ammonia, formaldehyde, concentrated sulphuric acid, concentrated nitric acid, selenious acid, molybdic acid / sodium molybdate were procured from E. Merck and Fischer Scientific. Colour Reagents - Marquis, Froehde, Meckle's were prepared according to United Nations publications. Reference material of Diacetylmorphine was of LGC, Germany.

\subsection{Sample Size}

A total of 252 suspected heroin samples were examined in 2019 for chemical constituents forwarded by the investigating agency. 


\subsection{Sample and standard preparation}

The samples and standard were dissolved in methanol and subjected to analysis.

\section{Methodology}

\subsection{Physical appearance}

The seized samples were found sealed and contained in plastic pouches, plastic containers, paper packets, different packing materials. The colour and morphology of the samples were observed and documented.

\subsection{Chemical tests}

Table 1: Description of Chemical tests conducted for detection of Heroin

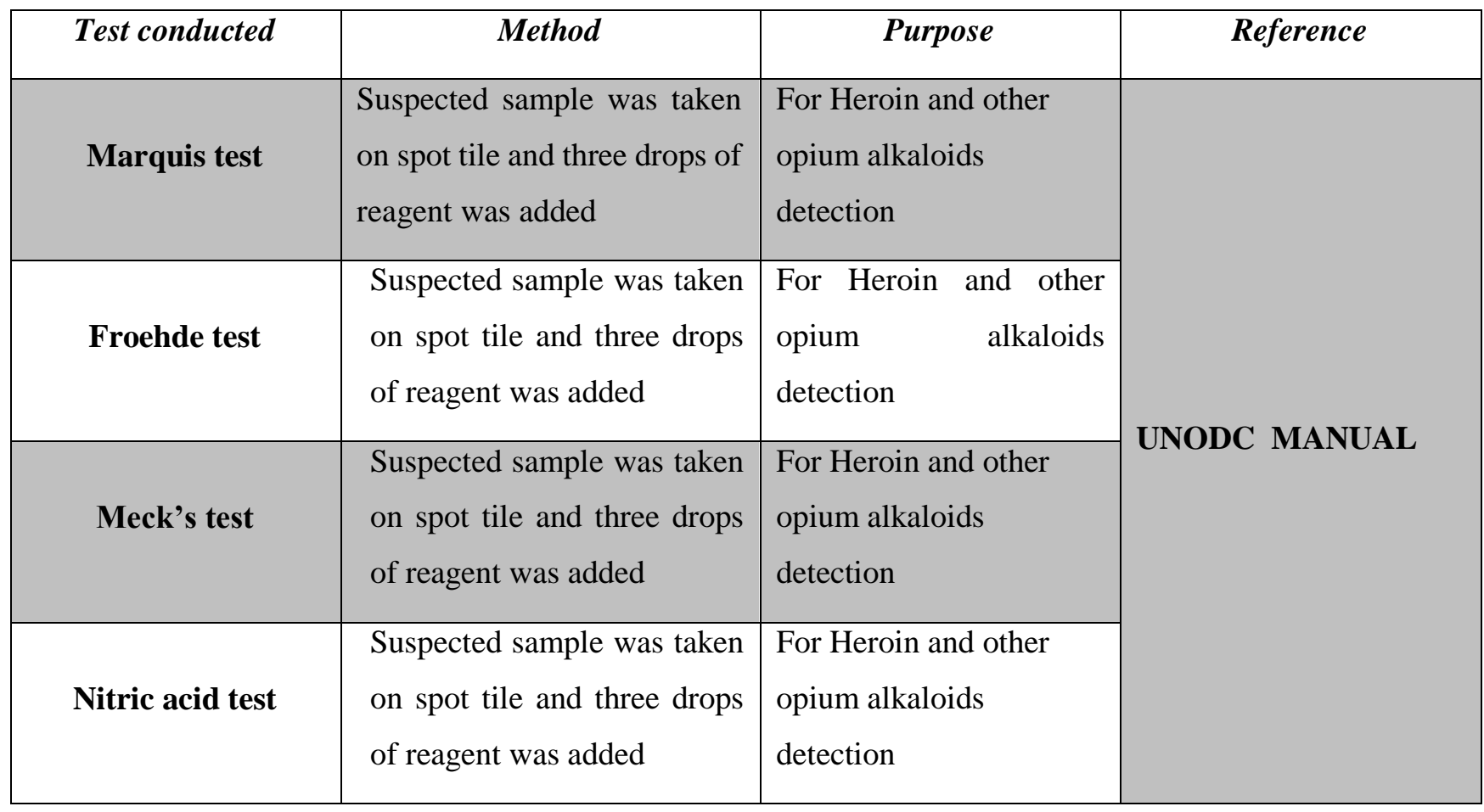

\subsection{Thin Layer Chromatography (TLC)}

\section{Developing solvent systems:}

System A: Methanol-Ammonia 100:1.5 v/v)

System B: Chloroform-Methanol (9:1 v/v)

\section{Sample and standard solutions preparation and spotting}

$5 \mathrm{mg}$ each of suspected heroin samples were dissolved in $1 \mathrm{ml}$ methanol and centrifuged. The supernatant clear liquids were separated into clean vials. $5 \mu 1$ of each sample was spotted on the TLC plates (pre-coated silica Gel plates $\mathrm{G} 60 \mathrm{~F}_{254} 20$ x $10 \mathrm{~cm} \times 0.2 \mathrm{~mm}$ thickness on aluminium from E-Merck). Ultra-violet lamp operating at $\lambda 254$, $366 \mathrm{~nm}$ - CAMAG, Switzerland was used for the location of spots after development in solvent system. Visualization of separated spots was carried out after spraying with Dragendorff' reagent followed by acidified Potassium Iodoplatinate reagent. 


\subsection{GC-MS operating condition}

\begin{tabular}{|c|c|}
\hline Sample preparation & $\begin{array}{l}\text { Solutions of the standards and samples are prepared in internal standard } \\
\text { solution at a concentration of } 1 \mathrm{mg} / \mathrm{ml}\end{array}$ \\
\hline System used & $\begin{array}{l}\text { Agilent GC (6890N), MSD (5977A), and an HP Chemstation data analysis. } \\
\text { injected using auto-sampler ( } 7683 \text { series) }\end{array}$ \\
\hline Column & $\begin{array}{l}30 \text { m length } \times 0.25 \mathrm{~mm} \text { ID; film thickness } \\
0.25 \mu \mathrm{m} \text { like DB-5 MS, }\end{array}$ \\
\hline Oven & Temperature Programming $-60{ }^{\circ} \mathrm{C}, 3 \mathrm{~min}$. hold, $40{ }^{\circ} \mathrm{C} / \mathrm{min}$ to $300{ }^{\circ} \mathrm{C}$ for $6 \mathrm{~min}$. \\
\hline Injector & Injector: Splitless, $240{ }^{\circ} \mathrm{C}$ \\
\hline Carrier gas & Helium, $1 \mathrm{ml} / \mathrm{min}$; constant flow \\
\hline MS parameters & $\begin{array}{l}\text { Ionization mode: } \mathrm{EI} \text { mode, } 70 \mathrm{eV} \\
\text { Transfer line temp: } 275^{\circ} \mathrm{C} \\
\text { Ion source temp: } 230{ }^{\circ} \mathrm{C} \\
\text { Scan parameters: } \mathrm{TIC} \text {, scan range: } 40 \text { to } 450 \mathrm{amu}\end{array}$ \\
\hline Sample injected & $1 \mu \mathrm{L}$ \\
\hline
\end{tabular}

\section{Observation and Results}

\subsection{Physical appearance}

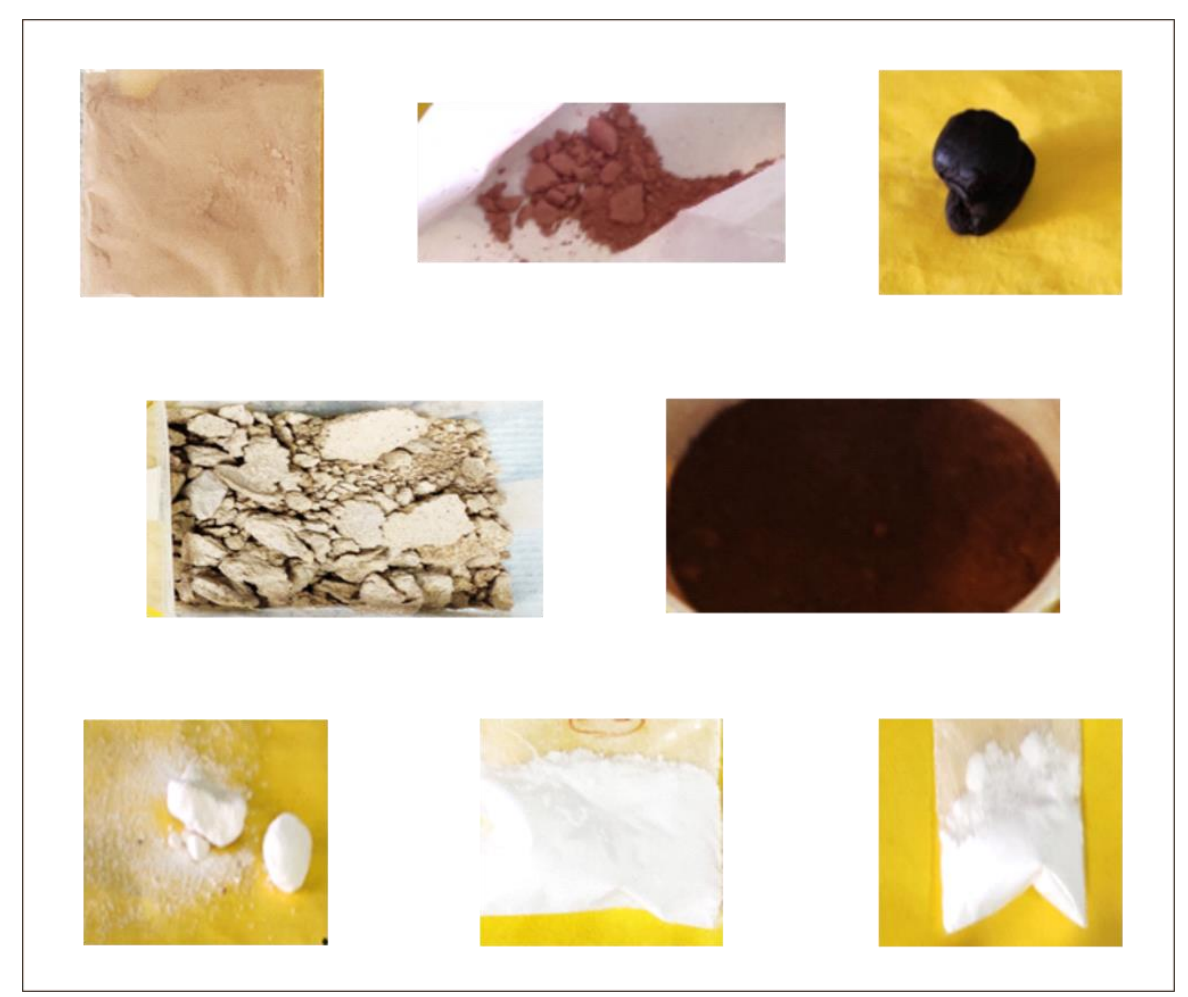

Figure 1: (Seized heroin samples showing different physical appearance) 
The colour of the seized samples varied from off- white, light brown, pinkish brown, brown to dark brown (shown in fig 1). The morphological texture of confiscated heroin samples varied from powdery material to coarse lumps to being sticky substances. In few of the samples. Prominent odour of vinegar was noticed in few samples.

\subsection{Presumptive Chemical tests for Diacetylmorphine/Heroin are presented in Table 2}

\begin{tabular}{|c|l|l|l|}
\hline Test conducted & Method & Observation & Inference \\
\hline Marquis test & $\begin{array}{l}\text { Suspected sample was taken } \\
\text { on spot tile and three drops } \\
\text { of reagent was added }\end{array}$ & $\begin{array}{l}\text { A violet/ reddish } \\
\text { purple colour was } \\
\text { observed }\end{array}$ & $\begin{array}{l}\text { Presence of Heroin and other } \\
\text { opium alkaloids }\end{array}$ \\
\hline Froehde tst & $\begin{array}{l}\text { Suspected sample was taken } \\
\text { on spot tile and three drops } \\
\text { of reagent was added }\end{array}$ & $\begin{array}{l}\text { A purple / green colour } \\
\text { was observed }\end{array}$ & $\begin{array}{l}\text { Presence of Heroin and other } \\
\text { opium alkaloids }\end{array}$ \\
\hline Meck's test & $\begin{array}{l}\text { Suspected sample was taken } \\
\text { on spot tile and three drops } \\
\text { of reagent was added }\end{array}$ & $\begin{array}{l}\text { A blue / green colour } \\
\text { was observed }\end{array}$ & $\begin{array}{l}\text { Presence of Heroin and other } \\
\text { opium alkaloids }\end{array}$ \\
\hline Nitric acid test & $\begin{array}{l}\text { Suspected sample was taken } \\
\text { on spot tile and three drops } \\
\text { of reagent was added }\end{array}$ & $\begin{array}{l}\text { A red-orange colour } \\
\text { was observed that } \\
\text { gradually changed to } \\
\text { green colour was } \\
\text { observed }\end{array}$ & $\begin{array}{l}\text { Presence of Heroin and other } \\
\text { opium alkaloids }\end{array}$ \\
\hline
\end{tabular}

Table 2: Results of Chemical tests conducted for detection of Heroin

\subsection{Thin Layer Chromatography (TLC)}

The hRf values in system A ranged from 46 to 48 and in system B from 37 to 39 respectively for diacetylmorphine. Visualization of separated spot of diacetylmorphine on different TLC plates was carried out by spraying with Dragendroff's followed by acidified potassium iodoplatinate reagents and was tallied with reference material of diacetylmorphine. It was observed that there were few more separated spots on the TLC plates apart from diacetylmorphine. For further identification and confirmation of different separated spots the samples were subjected GC-MS analysis.

\subsection{Gas Chromatography - Mass Spectrometry}

Gas Chromatography - Mass Spectrometry (GC-MS) is a hyphenated and popular technique for drug analysis. Gas chromatography separates components in the mixture and mass spectrometry measures exact molecular mass of ions as determined by their mass to charge ratio $(\mathrm{m} / \mathrm{z}){ }^{(18)}$. In this study also, Gas Chromatography - Mass Spectrometry (GC-MS) was used for seized forensic samples. The common adulterant compounds detected along with diacetylmorphine in the samples were acetaminophen, caffeine, phenobarbital, alprazolam, diazepam and few 


\section{AJAST}

Asian Journal of Applied Science and Technology

Volume 4, Issue 4, Pages 01-12, October-December 2020

opiates- acetylcodeine, monoacetylmorphine, morphine, and papervarine. Few novel adulterants were also detected in the confiscated samples namely dextromethorphan, trimethoprim, olanzapine and sertraline which have not been reported earlier in national capital territory of India. As there is ample literature available with respect to common adulterants, only the details of novel adulterants detected were included in this study. Table 3 represents the percentage of novel adulterants detected in the various examined samples analysed for suspected Heroin (252 in total) in Forensic Science Laboratory, Delhi (2019). Table 4 shows molecular weight and formula along with fragment ions. Fig 2- 6 shows individual mass spectrometer peaks and mass fragment ions. of adulterants and heroin.

Table 3: Percentage of Novel Adulterants found in various samples analysed for suspected Heroin (252 in total) in Forensic Science Laboratory, Delhi (2019)

\begin{tabular}{|l|c|c|}
\hline Drugs & Detected in Samples & Percentage \\
\hline Trimethoprim & 79 & $31 \%$ \\
\hline Dextromethorphan & 1 & $11 \%$ \\
\hline Sertraline & 5 & $0.39 \%$ \\
\hline Olanzapine & 252 & $1.98 \%$ \\
\hline $\begin{array}{l}\text { Total number of samples } \\
\text { analysed for suspected Heroin }\end{array}$ & & - \\
\hline
\end{tabular}

Table 4: $\mathrm{m} / \mathrm{z}$ and details of adulterants detected in heroin samples

\begin{tabular}{|c|c|c|c|c|c|}
\hline \multirow{5}{*}{$\begin{array}{l}\text { Main narcotic } \\
\text { detected } \\
\text {-Diacetylmorphine } \\
\text { - in Suspected } \\
\text { Heroin samples }\end{array}$} & $\begin{array}{c}\text { Adulterant } \\
\text { detected }\end{array}$ & $\begin{array}{l}\text { Mol weight } \\
\text { and Mol formula }\end{array}$ & $\begin{array}{l}\text { Base } \\
\text { peak }\end{array}$ & Fragment ions & Ref. \\
\hline & Dextromethorphan & $\begin{array}{l}271.4 \mathrm{~g} / \mathrm{mol} \\
\mathrm{C} 18 \mathrm{H} 25 \mathrm{NO}\end{array}$ & 271 & $\begin{array}{l}271,59,150,214, \\
171,203,31\end{array}$ & NIST \\
\hline & Trimethoprim & $\begin{array}{l}290.32 \mathrm{~g} / \mathrm{mol} \\
\mathrm{C}_{14} \mathrm{H}_{18} \mathrm{~N}_{4} \mathrm{O}_{3}\end{array}$ & 290 & $\begin{array}{l}290,259,275,243 \\
123,200,81\end{array}$ & NIST \\
\hline & Olanzapine & $\begin{array}{l}312.432 \mathrm{~g} / \mathrm{mol} \\
\mathrm{C}_{17} \mathrm{H}_{20} \mathrm{~N}_{4} \mathrm{~S}\end{array}$ & 242 & $\begin{array}{l}242,229,213,42, \\
312,198\end{array}$ & NIST \\
\hline & Sertraline & $\begin{array}{l}306.229 \mathrm{~g} / \mathrm{mol} \\
\mathrm{C}_{17} \mathrm{H}_{17} \mathrm{Cl}_{2} \mathrm{~N}\end{array}$ & 274 & $\begin{array}{l}274,276,159,262 \\
132,104\end{array}$ & NIST \\
\hline
\end{tabular}


Asian Journal of Applied Science and Technology Volume 4, Issue 4, Pages 01-12, October-December 2020
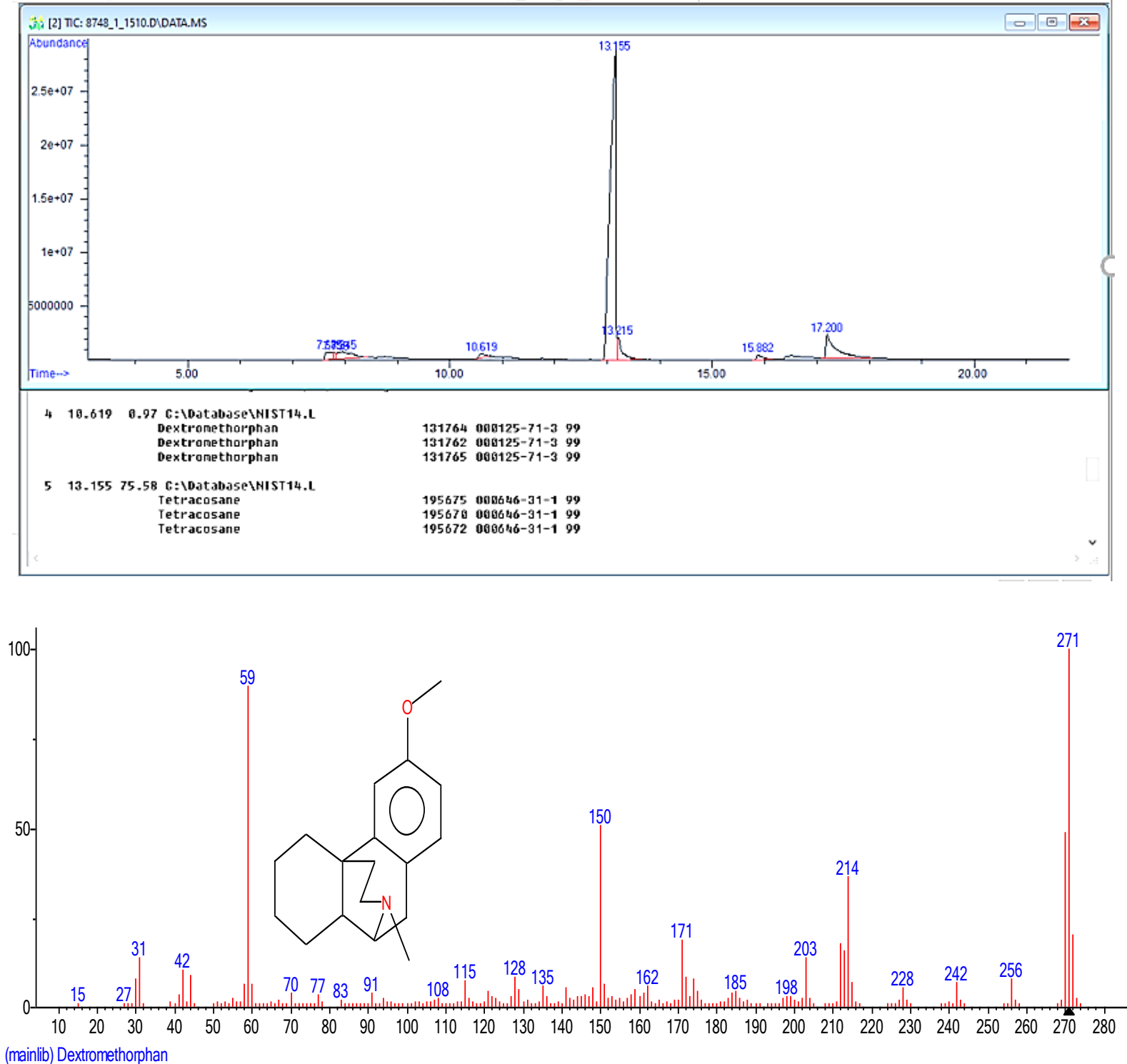

Figure 2: GC-MS peak and mass fragmentation of Dextromethorphan

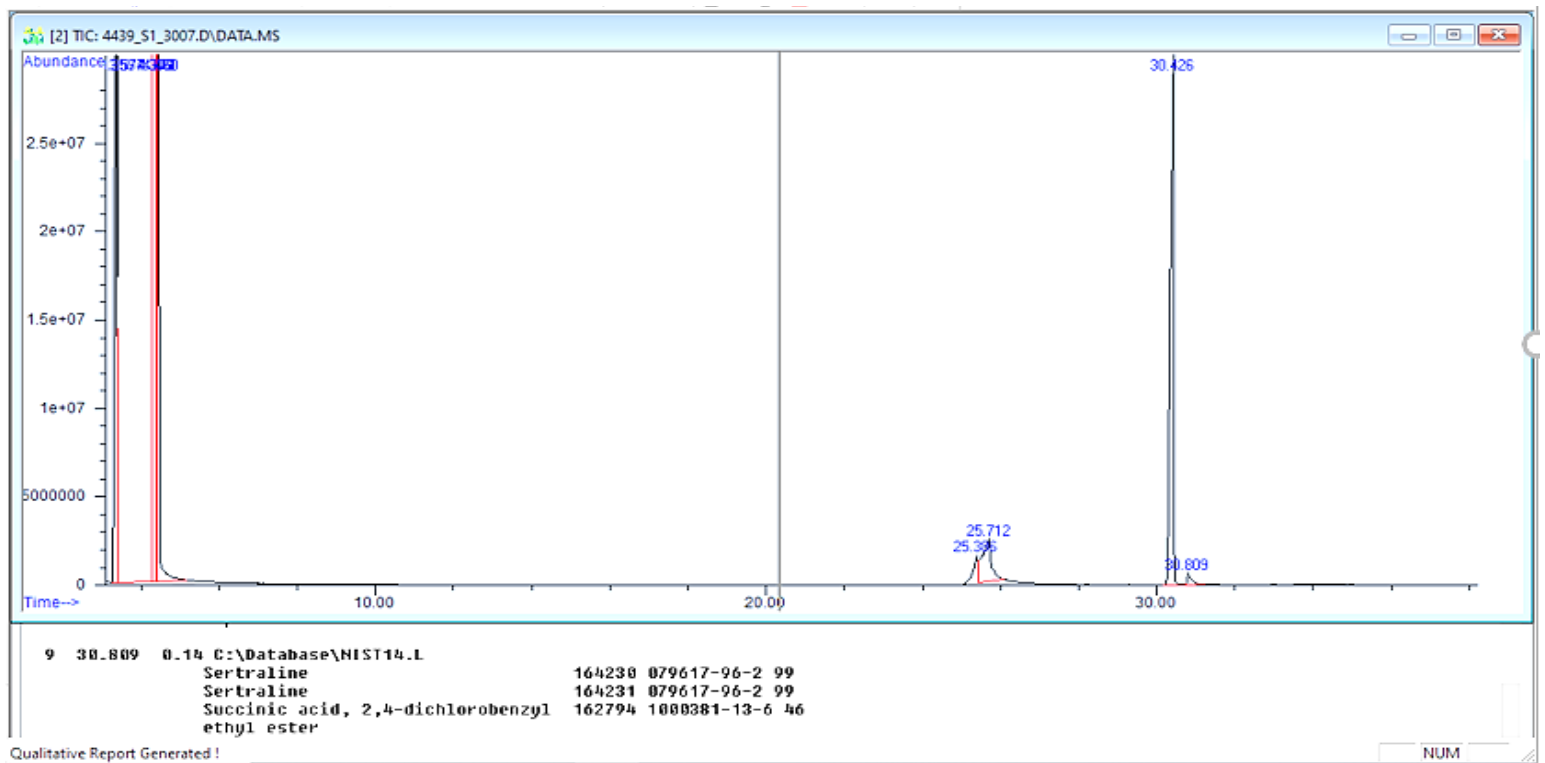




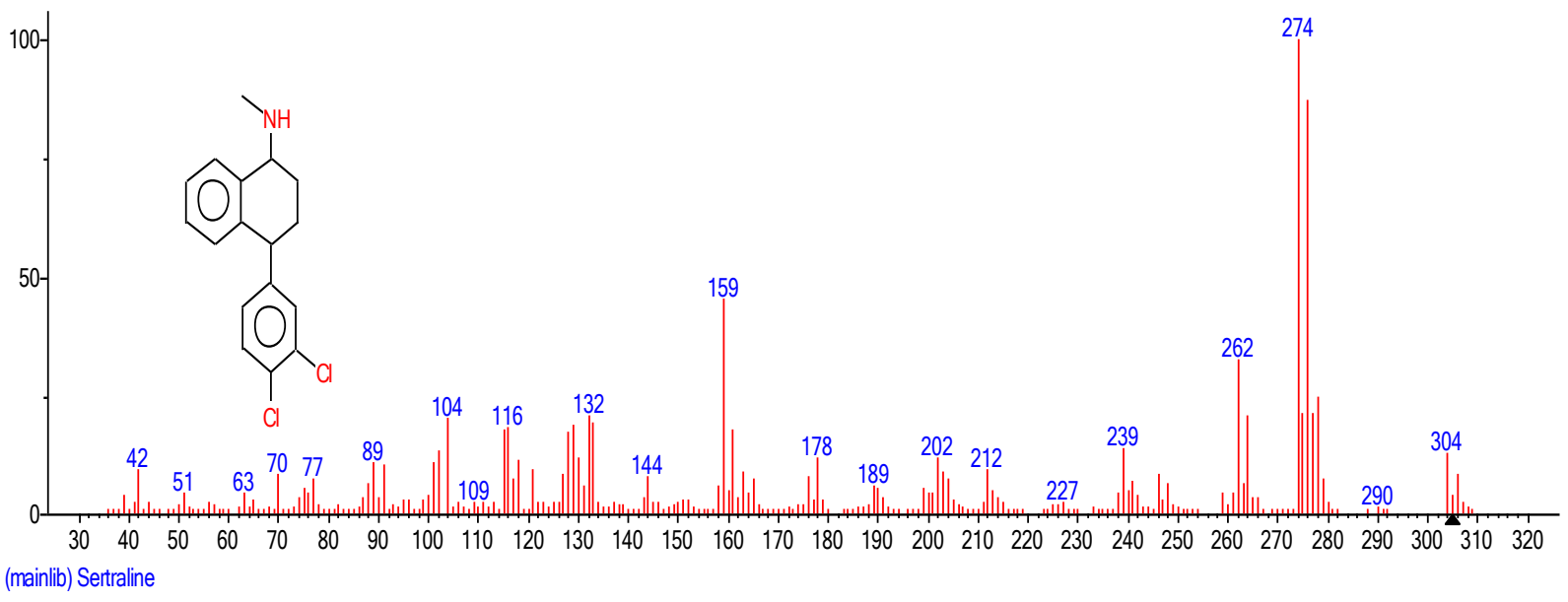

Figure 3: GC-MS peak and mass fragmentation of Sertraline
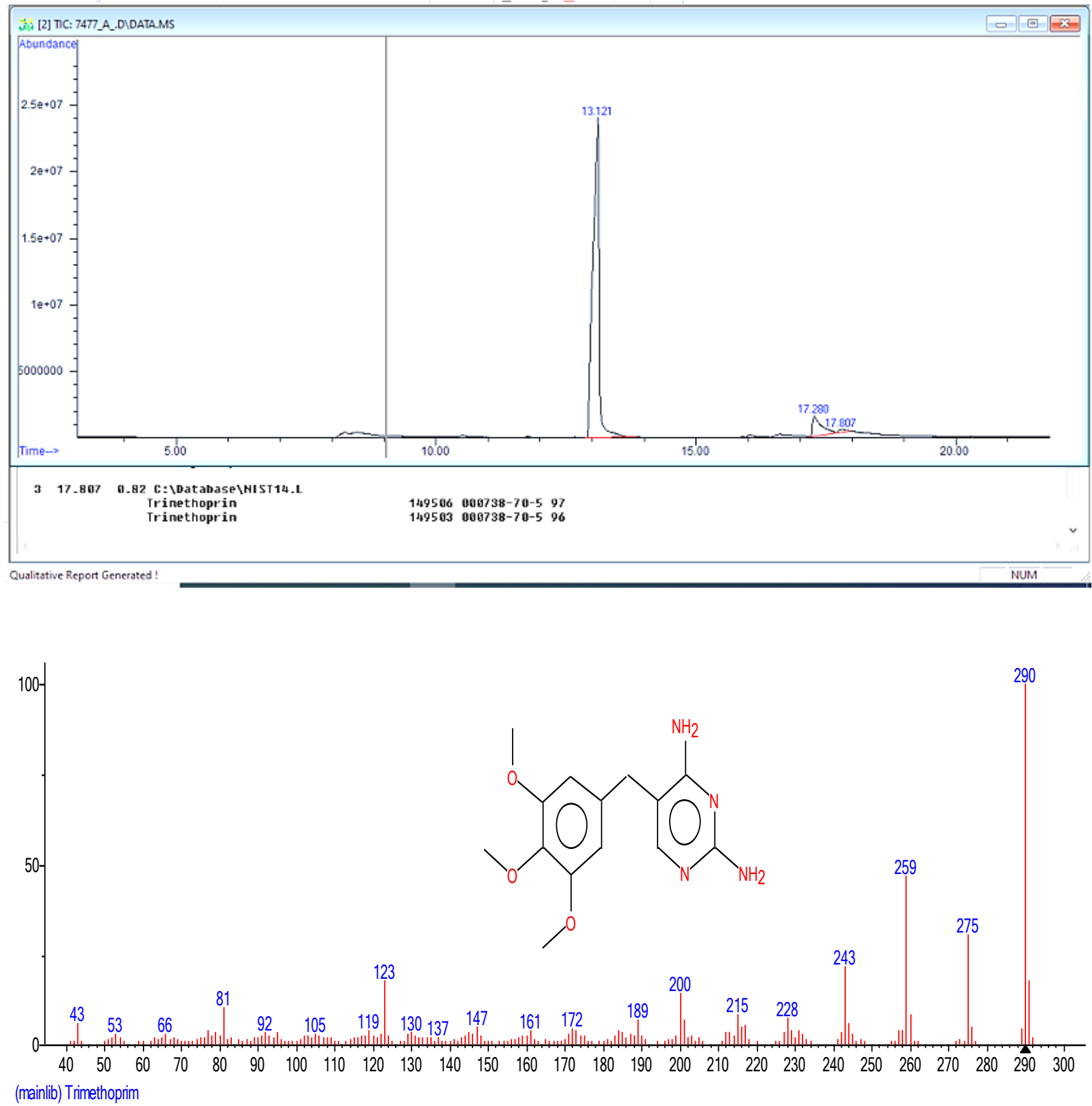

Figure 4: GC-MS peak and mass fragmentation of Trimethoprim 

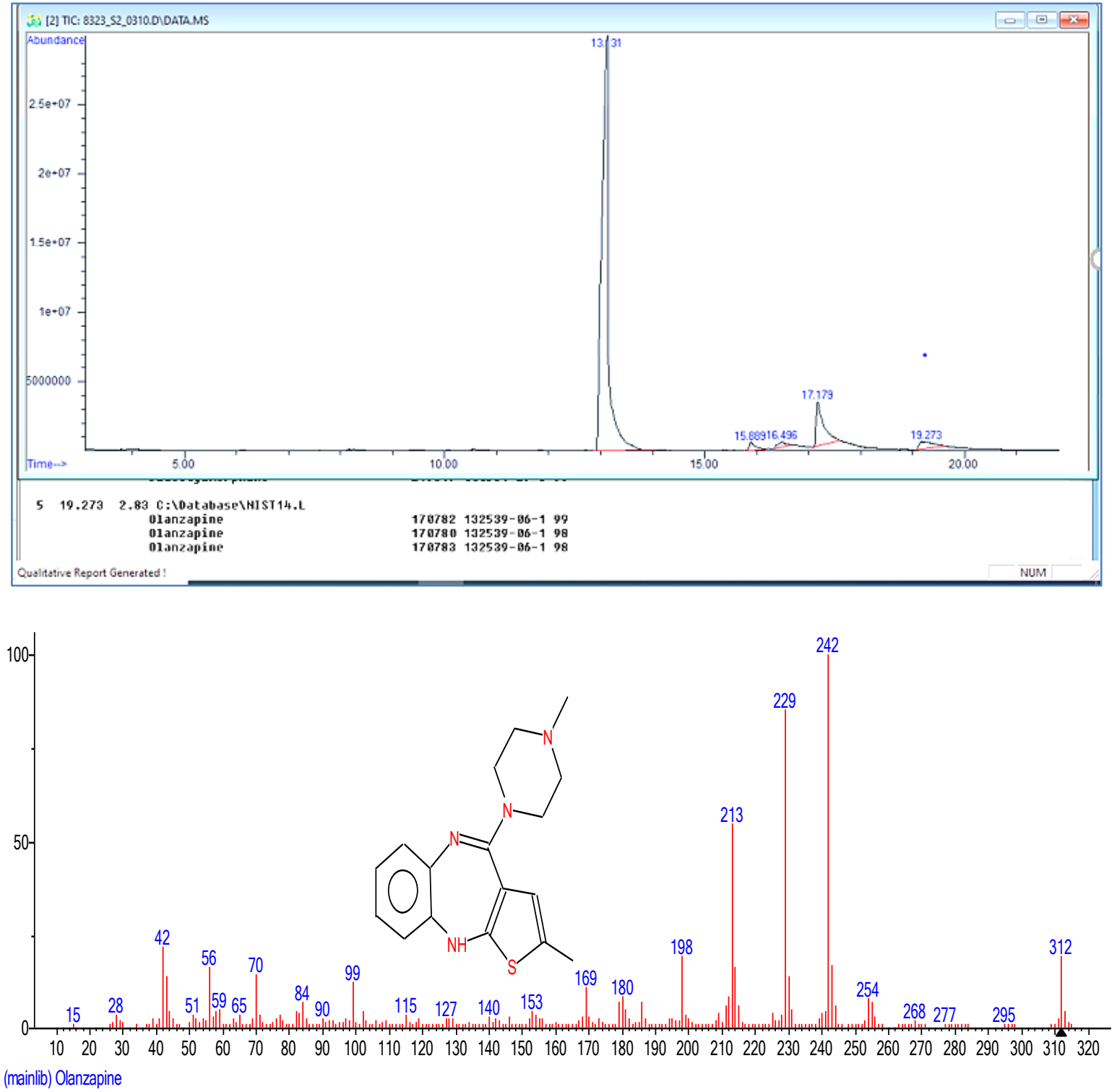

Figure 5: GC-MS peak and mass fragmentation of Olanzepine

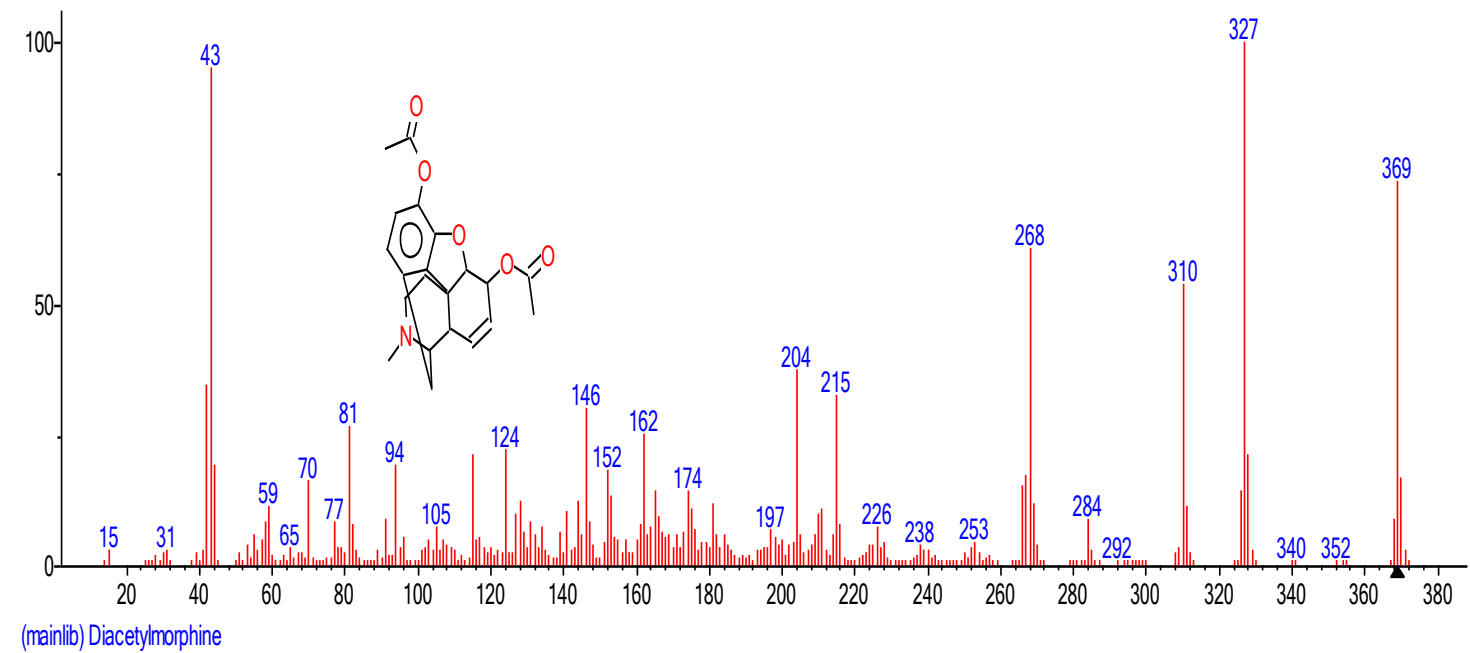

Figure 6: mass fragmentation of Heroin 


\section{Discussion}

The changing trends in use of adulterants to mask identity and befool legal authorities are a matter of great concern. Adulterated drugs often mimic or cause synergistic or antagonistic effect, often dangers associated with consumption of these drugs are hidden or unseen by abusers. It is therefore felt a need to share details of identified novel adulterants from heroin samples commonly sent to forensic laboratory in case of narcotic seizures.

Previous studies indicate the presence of various adulterants like procaine, fentanyl, cleenbuterol, diphenhydramine, acetaminophen, acetylcodeine, 6-monoacetylmorphine, caffeine, papaverine, noscapine, codeine, morphine, phenobarbital, acetylthebaol, alprazolam, diazepam, chloroquine, tramadol, quinine in illicit drugs ${ }^{(5)}$. Dextromethorphan, trimethoprim, olanzapine and sertraline were some novel adulterants detected by instrument GC-MS in seized heroin samples at FSL, Delhi.

Dextromethorphan is available as over the counter medicine for more than five decades, conveniently crosses blood-brain-barrier and activates sigma opioid receptors thereby suppressing cough reflex. The ultimate purpose is to calm the irritation in throat, but overdose may cause dissociative hallucination ${ }^{(19)}$. Use of dextromethorphan for recreational purposes has been well documented earlier, as it produces effects similar to ketamine and phencyclidine, and does not get readily converted into controlled substances. It's easy availability and inexpensive price becomes the appropriate reason for its addition to illicit heroin.

Olanzapine, an antipsychotic class of drug, used for treatment of schizophrenic and bipolar disorders of CNS has the potential to bind with opioid receptors. Literature suggest feeling of 'euphoria' and 'high' among users along with means to relax, aid sleep and relieve tension. Meagre information was available about abuse of olanzapine ${ }^{(20)}$.

Sertraline, an antidepressant drug, used for treatment of depression and other disorders like post-traumatic stress disorder, social anxiety disorder, is prescription drug for psychiatric treatment. Its side effects include diarrhoea, high rate of anxiety, sexual dysfunction, insomnia and increases activity of serotonin in brain. Acute overdose may manifest in lethargy, ataxia, tachycardia and seizures ${ }^{(21)}$. Studies are under process globally to understand whether opioid receptors are new target for antidepressant drugs.

Trimethoprim, is an anti-bacterial drug, also used in treatment of pneumonia and toxoplasmosis in people having HIV infections. Adulteration with antibiotic is mainly to increase the life of drug and prevent its degradation due to poor manufacturing processes, sub-standard packing, transportation, storage, etc., as it has to cross various hands before being finally consumed ${ }^{(9)}$.

Literature indicates that common adulterants fall in category of analgesic, stimulant, antidepressant and barbiturate groups of drugs (acetaminophen, caffeine, alprazolam, phenobarbital), but recent addition to this category is prescription drugs used in psychiatric treatment as uncommon adulterants. Addition of prescription drugs olanzapine and sertraline would have been to enhance the potency of clandestine prepared illicit drug formulations. Dextromethorphan can amplify the action of illicit drug due to its interaction with sigma opioid receptors. Also, the detection of trimethoprim in suspected heroin samples indicates its use would help in preservation of illicit heroin owing to its antibacterial property. However, further studies will be needed to notice the seemingly increasing 
Asian Journal of Applied Science and Technology Volume 4, Issue 4, Pages 01-12, October-December 2020

trend for the presence of afore mentioned adulterants in heroin for assessment of harm effects such adulterants can have on the abusers.

\section{Conclusion}

The examination of seized heroin samples analysed at FSL Delhi, in the year 2019 viz., physical appearance, chemical tests, TLC and GC-MS analysis indicate presence of new, uncommon adulterants: olanzapine, sertraline, trimethoprim and dextromethorphan. The non- medical use and illicit manufacture of controlled drugs have increased and so has the seizures by law enforcements officials. Hence, emphasis is essentially laid on building awareness and knowledge about presence and detection of these adulterants for forensic community. This also encourages such studies as a part of strategy to update about the recent trends emerging in illicit drug abuse. Identification of adulterants would enable the criminal judiciary system to keep vigilant eye on national and international crime.

\section{References}

1. UNODC. Analysis of Drug Markets. Vienaa: United Nations Publications, (2018).

2. INCB. Report of International Narcotics Control Bureau for 2019. INCB, (2019).

3. UNODC. Annual Drug Seizures. Vienna, (2019, May 12).

4. Drugbank. Opium: Drugbank. Retrieved from, (2019, May 12). https://www.drugbank.ca/drugs/DB11130

5. Akhgari M., Etemadi-Aleagha A., Jokar F., Street Level Heroin, an Overview on Its Components and Adulterants, Neuropathology of Drug Addictions and Substance Misuse, (2016), 1, pp. 867-877.

6. Huecker, M. R., Koutsothanasis, G. A., Abbasy, M. S., \& Marraffa, J.,Heroin. (2020). StatPearls [Internet].

7. Busardo F.P., Simona, P., Pacifici,R., Karch,S.B., The Never-Ending Public Health Issue of Adulterants in Abused Drugs, Journal of Analytical Toxicology, (2016), 1-2, doi: 10.1093/jat/bkw051

8. Barbera, N., Busardo, Indrato, \& Romano. (2013). The pathogenetic Role of adulterants in 5 cases of drug addicts with fatal outcome. Forensic Science International, 74-76.

9. Cole C, Jones L, McVeigh J, Kicman,A., Syed,Q., Bellis, M. Adulterants in illicit drugs: a review of empirical evidence. Drug Test Anal., (2011), 3:8996

10. Solimini R., Rotolo, M.C., Pellegrini, M., Minutillo, A., Pacifici, R., Busardò, F.P., Zaami, S.,Adulteration Practices of Psychoactive Illicit Drugs: An Updated Review, Current Pharmacological Biotechnology, (2017), 18(7):524-530.

11. Schneider, S., \& Meys, F.,Analysis of Illicit Cocaine and Heroin Samples Seized in Luxembourg From 2005-2010. Forensic Science International, (2011), 242-246.

12. Singh VM, Browne T, Montgomery J.,The Emerging Role of Toxic Adulterants in Street Drugs in the US Illicit Opioid Crisis. Public Health Rep. (2020), 135:6-10 
13. Broseus,J., Gentile,N., Pont, F.B., Gongora, J.M.G., Gaste,L., Essieva,P., Qualitative, Quantitative and Temporal Study of Cutting Agents for Cocaine and Heroin Over 9 Years, Forensic Science International, (2015), Dec 257:307-313, doi: 10.1016/j.forsciint.2015.09.014

14. Kaa E., Impurities, Adulterants and Diluents of Illicit Heroin. Changes During a 12-year Period, Forensic Science International, (1994), Feb: 64 (2-3): 171-179,

doi: 10.1016/0379-0738(94)90228-3

15. Egon Stahl, Thin layer chromatography- A laboratory handbook, (1969), (2nd Edn) 437.

16. Clarke ECG, Isolation and Identification of Drugs, (1978), London, Pharmaceutical Press, 1978

17. Clark CC A study of procedures for the identification of heroin. J. of Forensic Sciences, (1976), 22(2): 418

18. Chen, M., Rao, R., Zhang, Y., Zhong, C., \& Thelen, J.,A modified data normalization method for GC-MS-based metabolomics to minimize batch variation. (2014)., Springer Plus.

19. Indorato, F., Tuminoa,M., Occhipintia,S., Romanoa,G., Barbera,N.,The role of dextromethorphan in eight fatal overdoses: is it solely a cutting substance for heroin or could it be something more?, Euro mediterranean Biomedical Journal, (2015), 10(7):126-133

20. James, P. D., Fida, A. S., Konovalov, P., \& Smyth, B. P.,Non-medical use of olanzapine by people on methadone treatment. BJPsych bulletin, (2016), 40(6), 314-317. https://doi.org/10.1192/pb.bp.115.052886

21. Sharma, K. B. 18-(2017). Antidepressants: mechanism of action, toxicity and possible amelioration. Journal of Applied Biotechnology and Bioengineering, 437-448. 